\title{
lncRNA recruits RNAi and the exosome to dynamically regulate pho1 expression in response to phosphate levels in fission yeast
}

\author{
Sneha Shah, Sina Wittmann, ${ }^{1}$ Cornelia Kilchert, ${ }^{1}$ and Lidia Vasiljeva ${ }^{2}$ \\ Department of Biochemistry, University of Oxford, Oxford OX1 3QU, United Kingdom
}

\begin{abstract}
Numerous noncoding transcripts of unknown function have recently been identified. In this study, we report a novel mechanism that relies on transcription of noncoding RNA prt (pho1-repressing transcript) regulating expression of the pho1 gene. A product of this gene, Pho1, is a major secreted phosphatase needed for uptake of extracellular phosphate in fission yeast. prt is produced from the promoter located upstream of the pho1 gene in response to phosphate, and its transcription leads to deposition of RNAi-dependent H3K9me2 across the pho1 locus. In contrast, phosphate starvation leads to loss of $\mathrm{H} 3 \mathrm{~K} 9 \mathrm{me} 2$ and pho1 induction. Strikingly, deletion of Clr4, a H3K9 methyltransferase, results in faster pho1 induction in response to phosphate starvation. We propose a new role for noncoding transcription in establishing transient heterochromatin to mediate an effective transcriptional response to environmental stimuli. RNAi recruitment to prt depends on the RNA-binding protein Mmi1. Importantly, we found that the exosome complex and Mmi1 are required for transcription termination and the subsequent degradation of prt but not pho1 mRNA. Moreover, in mitotic cells, transcription termination of meiotic RNAs also relies on this mechanism. We propose that exosome-dependent termination constitutes a specialized system that primes transcripts for degradation to ensure their efficient elimination.
\end{abstract}

[Keywords: exosome; noncoding RNA; RNAi; transient heterochromatin; H3K9me; transcription termination] Supplemental material is available for this article.

Received September 5, 2013; revised version accepted December 20, 2013.

Recent analyses of the eukaryotic transcriptome have revealed numerous RNA polymerase II (Pol II) transcripts of unknown function produced from intergenic regions. These findings challenged the previous dogma that transcription is limited to well-defined functional units known as canonical genes (Rougemaille and Libri 2010). Interestingly, despite the fact that noncoding (nc) transcripts share features similar to mRNAs, such as the $5^{\prime}$ methylguanosine cap structure and a poly(A) (pA) tail, their fate and function differ. In contrast to mRNAs exported to the cytoplasm for translation, a large fraction of noncoding RNAs (ncRNAs) is retained in the nucleus and degraded by the exosome, the major $3^{\prime}-5^{\prime}$ nuclear and cytoplasmic RNA degradation machinery. Due to their unstable nature, these cryptic RNAs were first detected in cells defective in the nuclear exosome and were therefore termed cryptic unstable transcripts (CUTs) (Thiebaut et al. 2006). Recent analyses of mRNA and ncRNA maturation in budding yeast suggest that transcript fate depends on

\footnotetext{
${ }^{1}$ These authors contributed equally to this work.

${ }^{2}$ Corresponding author

E-mail lidia.vasilieva@bioch.ox.ac.uk

Article is online at http://www.genesdev.org/cgi/doi/10.1101/gad.

230177.113. Freely available online through the Genes \& Development

Open Access option.
}

the use of distinct mechanisms that are involved in RNA $3^{\prime}$ end formation (Kim et al. 2006; Tuck and Tollervey 2013). Unlike mRNAs, which have well-defined 3 ' ends formed upon endonucleolytic cleavage at the pA site by the cleavage and polyadenylation factor (CPF), CUTs have heterogeneous $3^{\prime}$ ends. This is due to early termination of their transcription by the Nrd1 complex that specifically interacts with Pol II and RNA (Arigo et al. 2006; Gudipati et al. 2008; Vasiljeva et al. 2008a). As a result, Nrd1 targets CUTs for degradation by the exosome (Vasiljeva and Buratowski 2006; Vasiljeva et al. 2008b). Due to their unstable nature, nc transcripts were initially thought to represent transcriptional noise. This view has been challenged by recent studies that proposed an important functional role for nc transcription in modulating gene expression; however, the exact mechanisms involved are not well understood.

In one of the described scenarios, the act of transcription per se rather than the ncRNA itself has a regulatory function by interfering with the expression of an overlapping protein-coding gene. It has been proposed that

(C) 2014 Shah et al. This article, published in Genes \& Development, is available under a Creative Commons License (Attribution-NonCommercial 3.0 Unported), as described at http://creativecommons.org/licenses/by$\mathrm{nc} / 3.0 \%$. 
transcriptional interference is achieved by blocking transcription factors or Pol II access to promoters /Greger et al. 2000). One of the best-studied examples occurs at the SER3 gene in Saccharomyces cerevisiae, where the $S E R 3$ promoter is overlapped by the repressive CUT SRG1. Transcription of SRG1 leads to increased levels of nucleosome occupancy in that region, which leads to SER3 repression. The resulting CUT is degraded by the exosome (Martens et al. 2004; Hainer et al. 2011).

Nc transcription can also affect gene expression by modulating the epigenetic state of the chromatin /Gullerova and Proudfoot 2010). Several studies suggest that the mechanisms involved depend on either the act of transcription per se, as was described for glucose-repressed genes (Houseley et al. 2008; Pinskaya et al. 2009), and/or on ncRNA itself, as described for the repression of heterochromatic regions mediated by RNAi (Buhler and Moazed 2007). The latter mechanism was suggested by studies in the fission yeast Schizosaccharomyces pombe, where nc transcription by Pol II at centromeres, telomeres, and mating type loci is required for formation of constitutive heterochromatin (Djupedal et al. 2005; Kato et al. 2005). Heterochromatic ncRNAs direct recruitment of the RNA-induced transcriptional silencing (RITS) complex, which comprises an argonaute family protein (Agol) and siRNA molecules (Noma et al. 2004; Verdel et al. 2004). siRNAs are thought to act as guide molecules to target RITS to nascent transcripts. RITS recruits the RNA-dependent RNA polymerase complex (RDRC) to produce dsRNA, which is processed into siRNA by Dicer (Dcr1) (Verdel et al. 2004; Buhler and Moazed 2007; Colmenares et al. 2007), and the Clr4-methyltransferase complex CLRC to methylate Lys9 of histone H3 (H3K9me) (Hong et al. 2005; Gerace et al. 2010). These events lead to the formation of heterochromatin, including the assembly of chromodomain proteins (Swi6 and Chp2) (Buhler and Moazed 2007).

Recent studies have revealed that in addition to constitutive heterochromatin, facultative heterochromatin can be formed across meiotic genes that are repressed in mitotic cells (Hiriart et al. 2012; Zofall et al. 2012; Tashiro et al. 2013). In contrast to the well-studied mechanism involved in the establishment of constitutive heterochromatin, the molecular details of how facultative heterochromatin is formed are not well understood. Recent reports proposed that $\mathrm{Clr} 4$ is recruited to meiotic genes differently from constitutive heterochromatin. Clr4 recruitment as well as $\mathrm{H} 3 \mathrm{~K} 9 \mathrm{me}$ across meiotic genes is mediated by the RNA-binding protein Mmil (Hiriart et al. 2012; Zofall et al. 2012; Tashiro et al. 2013), which binds directly to meiotic transcripts by recognizing DSR (determinant of selective removal) elements (Harigaya et al. 2006). Mmil also facilitates recruitment of the zinc finger protein Red1, which contributes to recruiting Clr4, subsequent H3K9me, and Swi6/Chp2 assembly. Finally, Mmil and Red1 mediate degradation of meiotic transcripts by the exosome complex (Harigaya et al. 2006; Sugiyama and Sugioka-Sugiyama 2011). Interestingly, the RITS complex is also found at meiotic genes, and its recruitment appears to depend on Mmil and Red1 (Hiriart et al. 2012; Zofall et al. 2012). However, whether RITS contributes to $\mathrm{H} 3 \mathrm{~K} 9 \mathrm{me}$ and transcriptional repression at these loci is not clear.

In this study, we focused on the pho1 gene, where we detected overlapping nc transcription driven by an upstream promoter. Previous studies in fission yeast have demonstrated that expression of the pho1 gene is carefully regulated in response to phosphate availability and that the encoded protein, a major secreted acid phosphatase, is involved in phosphate uptake. Phol is a homolog of the $S$. cerevisiae acid phosphatase Pho5. It is highly expressed during phosphate starvation and repressed in the presence of extracellular phosphate (Henry et al. 2011). The mechanism responsible for this regulation is not known. We describe that transcription of a long ncRNA (lncRNA), prt (pho1-repressing transcript), from an upstream promoter leads to repression of pho1 expression when phosphate is present. Moreover, under these conditions, we detected H3K9me 2 marks across the pho1 gene, which requires the Clr4 and RITS complexes. Similar to what has been described for meiotic genes, we show that RNAi recruitment to prt requires Mmil specifically binding to prt via DSR elements. We also show that expressing prt in trans is not sufficient for silencing, suggesting that pho1 is repressed in cis. This is different from the mechanism described for constitutive heterochromatin where ncRNAs act both in cis (Buhler et al. 2006) and in trans (Iida et al. 2008). In the absence of phosphate, nc transcription is no longer detected, leading to induction of the pho1 gene. Importantly, lack of Clr4 affects pho1 induction kinetics. These results suggest a new role for nc transcription in establishing transient heterochromatin to mediate an effective response to environmental stimuli (such as nutrient presence).

Interestingly, although prt and pho1 mRNA share the same 3' end, prt production is coupled to degradation by the exosome complex. We found that this specificity of targeting is achieved through the binding of Mmil to the DSR elements only present in prt. Surprisingly, inactivation of the nuclear exosome or Mmil resulted in increased levels of transcribing Pol II downstream from the pho1 pA site, suggesting that the exosome is important for transcription termination. We generalize these results by showing that meiotic transcripts are also dependent on the exosome and Mmil for transcription termination. This implies that the exosome may play a general role in transcription termination in fission yeast. We propose that fission yeast has a specialized system that primes transcripts for degradation, which may be important to ensure their efficient turnover.

\section{Results}

Two overlapping transcripts are synthesized from the phol locus

Expression of pho1 is regulated by the presence of extracellular inorganic phosphate. In the presence of phosphate, pho1 is expressed at a very low level, whereas, upon phosphate depletion, pho1 RNA (Fig. 1A,B, lanes 

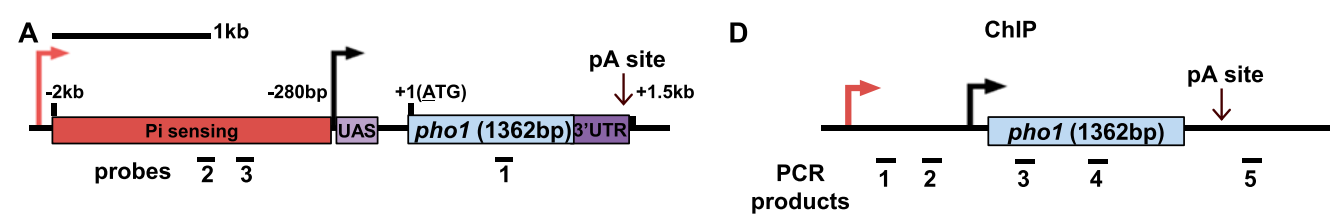

B

Northern Blot

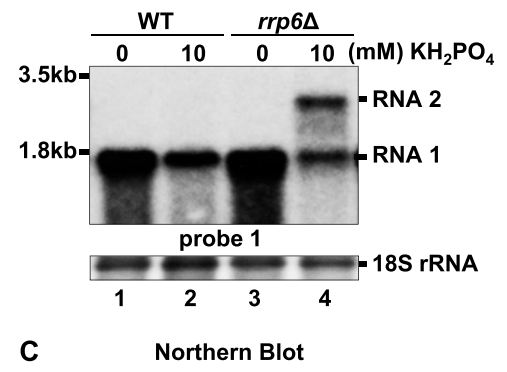

C

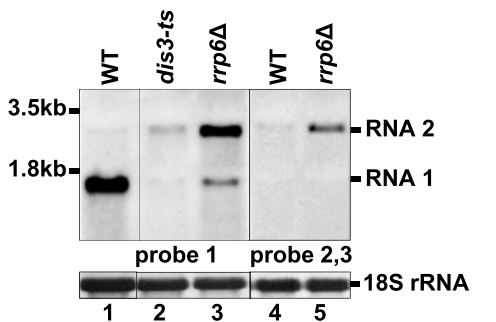

E

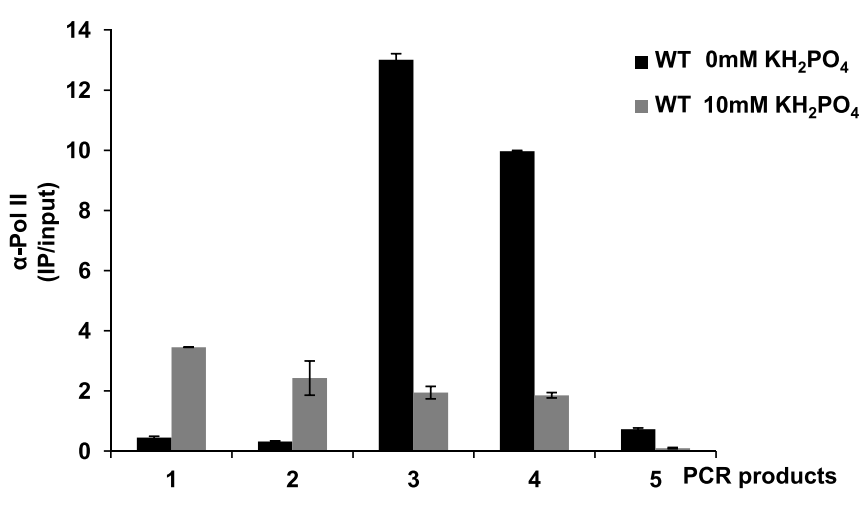

Figure 1. Two overlapping transcripts are made at the pho1 locus. $(A)$ pho1 schematic. The coding sequence is depicted in blue, the upstream activating sequence (UAS) is in purple, the phosphate sensing region is in red, and the 3' UTR is in dark purple. Probes are shown as black bars. $(B)$ Northern blot analysis of RNA isolated from wild-type (WT) and rrp6 $\Delta$ strains grown in EMMG medium with 0 or $10 \mathrm{mM} \mathrm{KH}_{2} \mathrm{PO}_{4}$. $(C)$ Indicated strains were grown in YES for Northern blot analysis. $(D)$ pho1 schematic showing locations of the PCR products from E. (E) Pol II ChIP experiments performed in wild-type cells grown in EMMG (0 or $\left.10 \mathrm{mM} \mathrm{KH}_{2} \mathrm{PO}_{4}\right)$. Quantification of the results from three independent experiments is shown; the error bars indicate the standard error. See also Supplemental Figure 1.

1,2; Henry et al. 2011) and protein levels are increased (Henry et al. 2011).

Expression of pho1 is believed to be driven from a promoter region located from -280 to -100 base pairs (bp) upstream of the pho1 ORF, and this region was found to be sufficient for transcription when positioned upstream of the YFP ORF (Carter-O'Connell et al. 2012). An additional regulatory element was predicted in the region between $2 \mathrm{~kb}$ and $280 \mathrm{bp}$ upstream of the pho1 ORF (Fig. 1A). Deletion of this region $(-2000$ to -280$)$ results in constitutive expression of pho1 mRNA and was therefore proposed to be essential for phosphate sensing (Henry et al. 2011; Carter-O'Connell et al. 2012). Interestingly, genome-wide tiling array data in a strain lacking the Rrp6 subunit of the exosome complex revealed the presence of a $5^{\prime}$-extended pho1 transcript, which overlaps with the proposed regulatory element. In contrast, under the same conditions (presence of phosphate) in wild-type cells, a pho1 transcript with a shorter 5 ' untranslated region (UTR) was detected (Wilhelm et al. 2008). To investigate the possibility that more than one transcript is synthesized from the pho1 locus, we analyzed steady-state levels of pho1 RNA in wild type and $\operatorname{rrp} 6 \Delta$.

Indeed, two pho1 transcripts were detected in $\operatorname{rrp} 6 \Delta$ (Fig. 1B, lane 4). One of these, an $\sim 1.5$-kb RNA (RNA1), was also present in wild type, and its size corresponds to the transcript produced from the annotated pho1 promoter. Levels of this RNA increase in the absence of phosphate in both strains, in agreement with a previously reported increased phosphatase activity under these conditions (Henry et al. 2011). This suggests that RNA1 is likely to encode for Phol protein. A longer pho1 transcript of $\sim 2.5 \mathrm{~kb}$ (RNA2) was detected only in the exosome mutant in the presence of phosphate (Fig. 1B, lane 4). Based on the size of RNA2, it is likely to represent the previously annotated 5'-extended pho1 RNA. Indeed, this was confirmed by using a strand-specific RNA probe generated from the region upstream of pho1 that detected only RNA2 but not RNA1 (Fig. 1C, lanes 4,5). In contrast, both RNAs were detected using an ORF-specific probe (Fig. 1C, lanes 2,3). No signal was detected using a probe detecting antisense transcripts (data not shown). Notably, in the presence of phosphate, accumulation of the longer transcript (RNA2) in $\operatorname{rrp} 6 \Delta$ correlated with a decrease in the levels of RNA1 as compared with wild type (Fig. 1B, lanes $2,4)$. The decrease in the RNA levels was even more striking in a dis3 mutant (Fig. 1C, lane 2). To examine the possibility that RNA2 is also produced in wild-type cells, Pol II occupancy across the pho1 locus was analyzed by chromatin immunoprecipitation (ChIP) in the presence and absence of phosphate (Fig. 1D,E). Interestingly, in the presence of phosphate, Pol II levels were high across 
the region upstream of the pho1 promoter (specific for RNA2). This implies that RNA2 is transcribed under these conditions in wild-type cells but rapidly degraded by the exosome. In contrast, during phosphate starvation, no Pol II was detected in this region. This coincided with an increase in Pol II occupancy across the pho1 ORF, in agreement with the increased levels of RNA1 (Fig. 1B, lane 1).

To map the exact 5' and 3' ends of both transcripts, we used cRACE (Supplemental Fig. 1A). Sequencing of the cDNA clones revealed that all pho1 transcripts end 135 nucleotides (nt) downstream from the stop codon (Supplemental Fig. 1B-D). However, three separate transcription start sites (TSSs) were mapped at $-1198 \mathrm{nt},-324 \mathrm{nt}$, and $-52 \mathrm{nt}$ upstream of the start codon $(\underline{\mathrm{ATG}}=+1)$. All clones from the wild-type strain corresponded to the transcript produced from the -52 TSS. However, the majority of clones (five out of seven) from $\operatorname{rrp} 6 \Delta$ were produced from the -1198 TSS (Supplemental Fig. 1D). This is in a good agreement with the Northern blot data and confirms that the two major pho1 transcripts are transcribed from two independent promoters and differ in their 5' UTRs. A transcript produced from the -324 TSS was not detected by Northern blot, suggesting that transcription from this site is very inefficient.

We conclude that two overlapping transcripts are produced in the same orientation from the pho1 locus in the presence of phosphate: RNA1 $(\sim 1.5 \mathrm{~kb})$, produced from the previously annotated promoter (-52 TSS), and RNA2 $(\sim 2.5 \mathrm{~kb})$, which starts $>1 \mathrm{~kb}$ further upstream $(-1198$ TSS) and accumulates in exosome mutants. In the absence of phosphate, only RNA1 can be detected in wildtype and $\operatorname{rrp} 6 \Delta$ strains.

\section{Nc transcription represses the downstream mRNA expression}

We identified two pho1 transcripts that are produced in the presence of phosphate, one of which is produced from a promoter located upstream of the annotated pho1 promoter in the presence of phosphate only. While it was shown previously that the promoter element driving expression of RNA1 can drive YFP expression, it was never verified that Phol expression also relies on this promoter. To address this, we generated strains where one of the promoters was deleted (Fig. 2A). As expected, deleting $346 \mathrm{bp}$ from the predicted mRNA promoter region resulted in complete loss of RNA1 (Fig. 2B, lanes 1,3 ), coinciding with loss of phosphatase activity (Fig. 2C). Similarly, deletion of the RNA1 promoter in a $\operatorname{rrp} 6 \Delta$ background where RNA2 is stabilized also yields no phosphatase activity (Fig. 2C; data not shown).

Replacing 234 bp from the predicted promoter driving RNA2 expression with a $\mathrm{ura}^{+}{ }^{+}$cassette resulted in constitutive expression of RNA1 and high levels of phosphatase
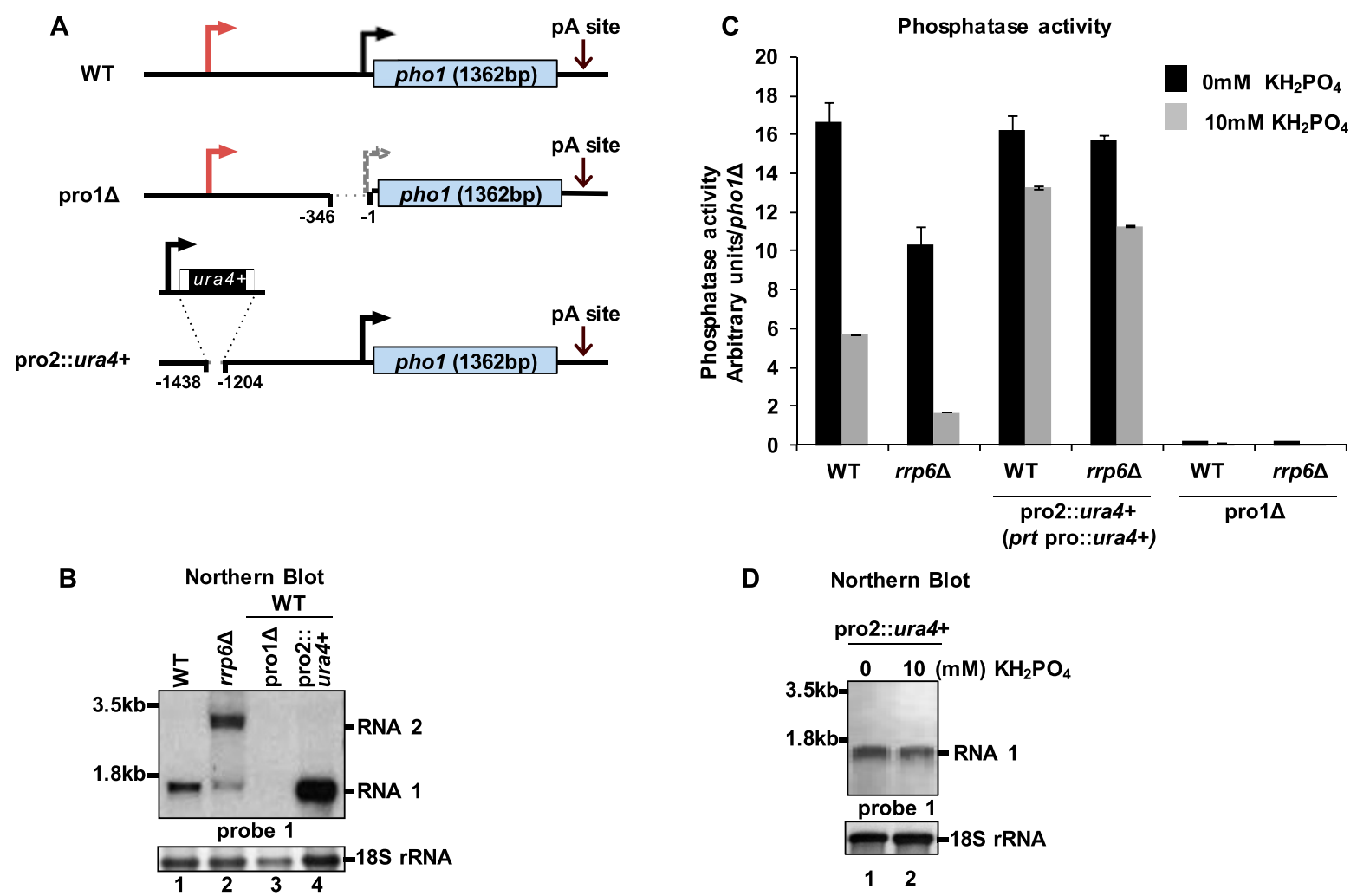

Figure 2. Expression of prt negatively affects pho1 RNA and protein levels. (A) Schematic representation of the promoter deletion strains. $(B)$ Northern blot analysis of RNA levels in the indicated strains grown in YES. $(C)$ Analysis of phosphatase activity for the strains in $A$. Strains were grown in EMMG medium $\left(0\right.$ or $\left.10 \mathrm{mM} \mathrm{KH}_{2} \mathrm{PO}_{4}\right)$. Values were normalized to those from a pho1 $\Delta$ strain. $(D)$ Northern blot analysis of indicated strain from the experiment in $C$. 
activity (Fig. 2C,D, lanes 1,2), in agreement with previous reports implicating the region -280 to -2000 in phosphate sensing. As the $5^{\prime}$-extended RNA is present only under repressive conditions, we suspected that it might play a role in repressing RNA1 transcription. Thus, we used the strain with the RNA2 promoter deleted to analyze levels of RNA1 compared with wild type. Strikingly, a substantial increase in RNA1 levels (approximately threefold) (Fig. 2B, cf. lanes 1 and 4) and phosphatase activity (threefold to sixfold) (Fig. 2C) was observed in the strains lacking the nc promoter. These data suggest that only RNA1 encodes Pho1, whereas RNA2 is likely noncoding. It appears to have a regulatory function by repressing pho1 in response to phosphate. Therefore, we now refer to the pho1 lncRNA as prt (pho1-repressing transcript).

RNAi is involved in phol silencing in the presence of phosphate via methylation of H3K9

We noticed that pho1 mRNA and protein levels were lower in $\operatorname{rrp} 6 \Delta$ compared with wild type (Figs. 1B, 2C). Intriguingly, the kinetics of pho1 mRNA induction in wild type is quite slow compared with other inducible genes (Fig. 3A; Kim et al. 2012). Furthermore, in rrp6s, the induction was delayed compared with wild type, resulting in lower mRNA levels (Fig. 3A) and reduced phosphatase activity (Fig. 3B). However, after $12 \mathrm{~h}$ in the absence of phosphate, equal levels of RNA and Phol protein were observed in both strains (data not shown). We speculated that changes in the chromatin environment across pho1 might underlie the delay in the activation of pho1. In support of this idea, complete deletion of the prt promoter led to equal levels of Phol expression in the presence and absence of phosphate in both strains (Fig. 2C).

To determine whether pho1 expression is regulated by chromatin modifications, H3K9me2 levels across this locus in wild-type and $\operatorname{rrp} 6 \Delta$ cells were analyzed in the presence of phosphate. Strikingly, H3K9me2 can be detected across pho1 by ChIP (Fig. 4A,B). In contrast, no enrichment above background was observed across the constitutively expressed adh1 gene (data not shown). $\mathrm{H} 3 \mathrm{~K} 9 \mathrm{me} 2$ levels were further increased in $\operatorname{rrp} 6 \Delta_{\text {; }}$ this is in agreement with the decreased mRNA expression and phosphatase activity observed in this strain (Fig. 2B,C). We next asked whether the RNAi pathway is involved in depositing H3K9me2 marks across pho1. In particular, H3K9me2 levels were assessed in the absence of Agol, a component of the RITS complex. Indeed, partial loss of H3K9me2 was observed upon Agol deletion lago1s and ago1 $\operatorname{rrp} 6 \Delta$ strains) (Fig. 4B). A loss of H3K9me2 was also observed in centromeric regions (data not shown). Moreover, recruitment of Agol to pho1 could be detected by
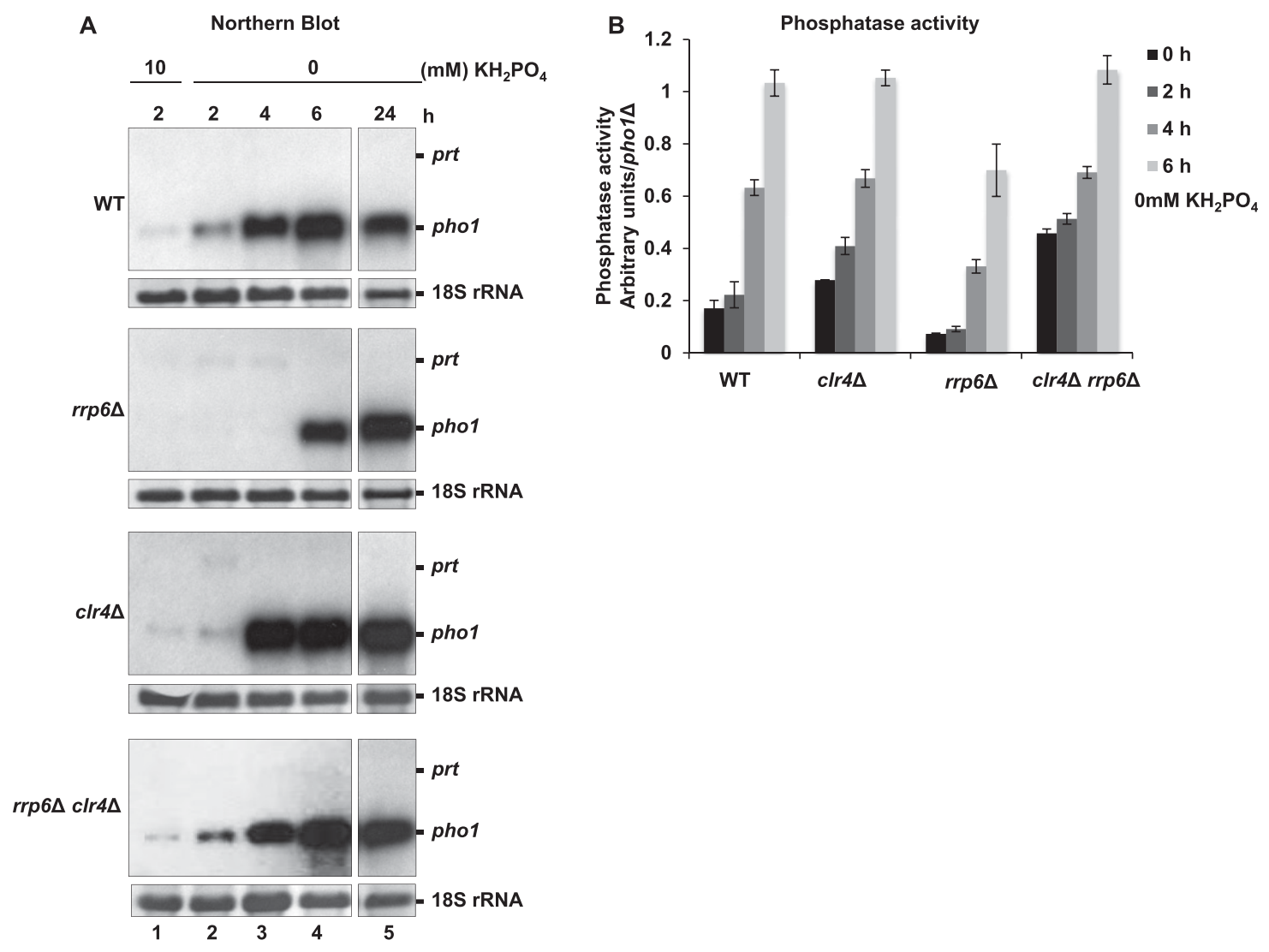

Figure 3. pho1 induction kinetics. Experiments were performed in the indicated strains grown in $\mathrm{EMMG}_{\mathrm{with}} 10 \mathrm{mM} \mathrm{KH}_{2} \mathrm{PO}_{4}$ and then shifted to $0 \mathrm{mM} \mathrm{KH}_{2} \mathrm{PO}_{4}$ for 2, 4, 6, and $24 \mathrm{~h}$. Cells were pelleted for para-Nitrophenylphosphate (PNPP) assays and RNA extraction. (A) Northern blot analysis for pho1 from samples collected during the time course. The same probe as in Figure $1 \mathrm{~A}$ was used. (B) Phosphatase activity measured for the strains in $A$. 
Shah et al.

A

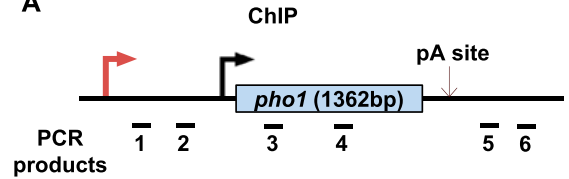

B

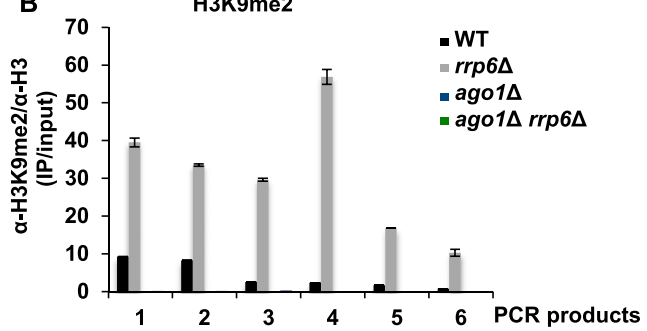

C

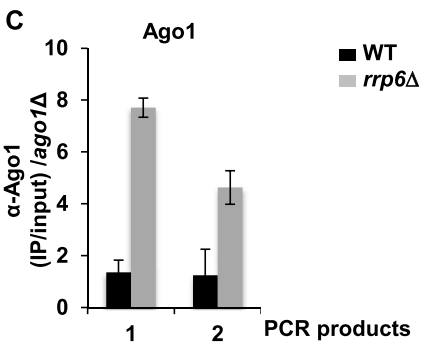

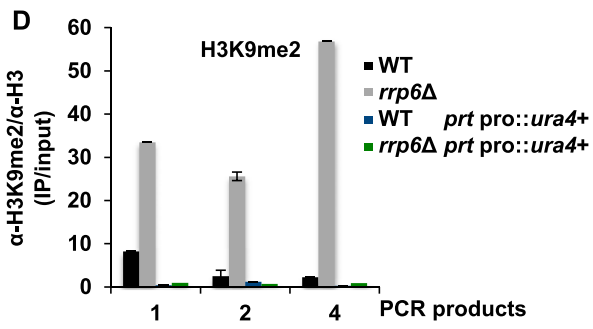

E 30 H3K9me2

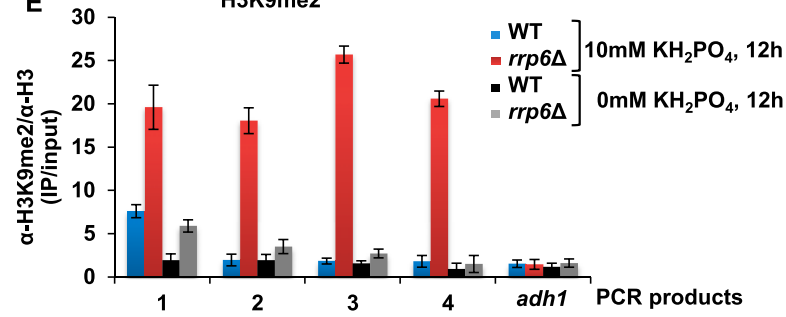

Figure 4. Expression of prt mediates deposition of H3K9me2 marks across pho1. (A) Schematic representation of the pho1 gene. Black bars show locations of the PCR products. $(B-E)$ ChIP experiments were performed in the strains indicated. Cells were grown in YES for the experiments in $B-D$ and in EMMG $\left(0\right.$ or $\left.10 \mathrm{mM} \mathrm{KH}_{2} \mathrm{PO}_{4}\right)$ for the experiments in $E$. Quantification of the results from three independent experiments are shown; the error bars indicate the standard error. $(B) \mathrm{ChIP}$ analysis of $\mathrm{H} 3 \mathrm{~K} 9 \mathrm{me} 2$ in the strains indicated. (C) Ago1 ChIP. (D) H3K9me2 ChIP analysis in cells lacking the prt promoter. (E) H3K9me2 ChIP in the indicated strains grown in EMMG $\left(0\right.$ and $\left.10 \mathrm{mM} \mathrm{KH}_{2} \mathrm{PO}_{4}\right)$. See also Supplemental Figure 2.

ChIP (Fig. 4C). Reduction in H3K9me2 levels was also observed in the absence of Dicer (dcr1 $1 \Delta)$ as well as in the catalytic mutants of Dicer and Agol (Supplemental Fig. $2 \mathrm{~A}, \mathrm{~B}$, suggesting that RITS contributes to $\mathrm{H} 3 \mathrm{~K} 9 \mathrm{me} 2$. Similarly, an Rdp1 mutant $(r d p 1 \Delta)$ showed reduced levels of H3K9me2 compared with wild type. Upon deletion of Clr4, H3K9me2 levels were further reduced compared with the levels observed in RITS mutants, suggesting that $\mathrm{Clr} 4$ can also be recruited independently of RITS, as was proposed for meiotic transcripts. Clr4 recruitment is also known to require Red1. We therefore analyzed H3K9me2 levels in red1s (Supplemental Fig. 2C). In agreement with published data, H3K9me2 levels were decreased in the mutant strain compared with wild type.

Nc transcription is required for RNAi recruitment and heterochromatin formation across phol

Since H3K9me2 marks across pho1 were found under repressive conditions, we tested whether heterochromatic marks are linked to the expression of prt RNA. We show that, in the absence of prt transcription (due to promoter deletion), loss of H3K9me2 was observed in wild-type and rrp6s strains (Fig. 4D), while centromeric heterochromatin remained unaffected (data not shown). Furthermore, after a 12-h shift to phosphate-deficient medium, when prt RNA was not expressed, H3K9me2 was no longer detected in wild type (Fig. 4E). Low levels of H3K9me2, comparable with the background, were still detected across the pho1 locus in rrp6 6 cells at this time point. We believe that these low levels of $\mathrm{H} 3 \mathrm{~K} 9 \mathrm{me} 2$ can be considered negligible, as mRNA levels are equal to those observed in the wild-type strain under these conditions (Fig. 3A). We conclude that prt transcription is necessary for $\mathrm{H} 3 \mathrm{~K} 9 \mathrm{me} 2$ at pho1, while lack of nc transcription (in the absence of phosphate) leads to the loss of H3K9me2.

We noticed a remarkable correlation between loss of $\mathrm{H} 3 \mathrm{~K} 9 \mathrm{me} 2$ and induction of mRNA. To investigate whether RNAi-directed H3K9me2 has a role in pho1 regulation, we next studied pho1 induction kinetics in clr $4 \Delta$ and clr $4 \Delta$ rrp $6 \Delta$ cells. Strikingly, loss of Clr4 results in faster pho1 induction in response to phosphate starvation (Fig. 3A,B). Moreover, deletion of Clr4 in an rrp64 background entirely suppresses the delayed kinetics observed in the rrp6s single mutant. These results suggest a repressive role for $\mathrm{Clr} 4$ and $\mathrm{H} 3 \mathrm{~K} 9 \mathrm{me} 2$ at the pho1 locus. H3K9me leads to heterochromatin formation by recruiting Swi6. Indeed, Swi6 was previously detected at the pho1 locus (Cam et al. 2009). Moreover, a slight increase in pho1 levels is observed in swibs in the 
presence of phosphate (Supplemental Fig. 2F, cf. lanes 1 and 2), and this effect is even more pronounced upon loss of another chromodomain protein, Chp2 (Supplemental Fig. 2F). This implies that the role for transient H3K9me2mediated heterochromatin at the pho1 region is to facilitate a timely transcriptional response to environmental stimuli.

The exosome is required for termination of prt transcription

It is well established that the exosome complex is a key player in regulating gene expression at the post-transcriptional level. However, elevated levels of H3K9me2 marks found in $\operatorname{rrp} 6 \Delta$ cells prompted us to test whether the decrease in pho1 mRNA levels in this strain is due to transcriptional repression. The Pol II profile at pho1 was analyzed in wild-type and $\operatorname{rrp} 6 \Delta$ cells grown under repressive conditions. Significant enrichment in Pol II levels over background was seen in the region encoding the prt upstream of pho1, suggesting that it is transcribed under these conditions (Fig. 5A-C). In support of a transcriptional repression, lower levels of Pol II were detected across the pho1 ORF in rrp $6 \Delta$ cells compared with wild type, in agreement with the lower steady-state mRNA levels and higher $\mathrm{H} 3 \mathrm{~K} 9 \mathrm{me} 2$ levels observed in the $\operatorname{rrp} 6 \Delta$.
Pol II levels were unchanged at adh1 (Supplemental Fig. S3). To our surprise, we also found decreased levels of Pol II in the region unique to prt in $\operatorname{rrp} 6 \Delta$. This is in striking contrast to the Northern blot data showing higher levels of prt in $\operatorname{rrp} 6 \Delta$ (Fig. 1B) suggesting that this RNA is degraded by the exosome.

Interestingly, we noticed that despite the lower overall Pol II occupancy in the exosome mutant, Pol II levels did not drop past the pA site in $\operatorname{rrp} 6 \Delta$, as was the case in the wild-type cells (Fig. 5A-C). This suggested a potential transcription termination defect in $\operatorname{rrp} 6 \Delta$. Indeed, 3'extended transcripts were detected in the exosome mutant but not in wild type by RT-PCR using primers spanning the pA site (Supplemental Fig. 4A). Readthrough levels in $\operatorname{rrp} 6 \Delta$ were comparable with those observed upon mutation of $d h p 1$ (Shobuike et al. 2001; Xiang et al. 2009), which encodes the homolog of budding yeast Rat1 and human Xrn2, a nuclear 5'-3' exonuclease involved in transcription termination (Kim et al. 2004b, 2006; West et al. 2004). As expected, transcriptional runon (TRO) analysis performed in the $d h p 1$ mutant revealed nascent RNA beyond the pA site (Supplemental Fig. 4B), which confirms that Pol II fails to terminate in this mutant. To test the possibility of the exosome being involved in Dhp1-dependent transcription termination, we generated double mutants (rrp6sdhp1-ts) and com-

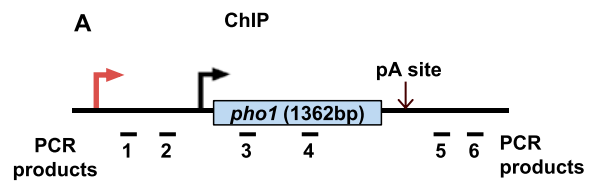

D Transcription Run On
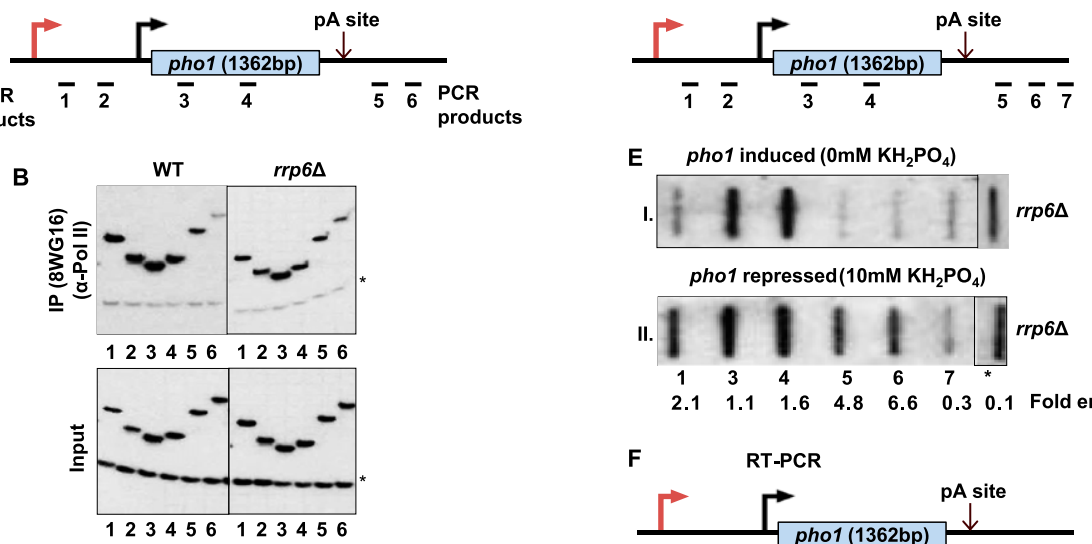

E pho1 induced $\left(0 \mathrm{mM} \mathrm{KH}_{2} \mathrm{PO}_{4}\right)$
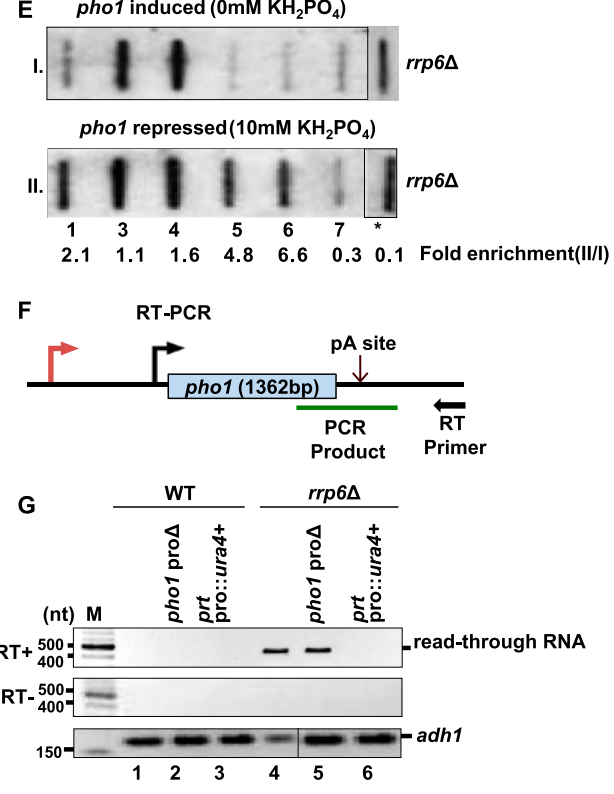

Figure 5. Rrp6 is required for transcription termination of prt. $(A)$ pho1 schematic showing locations of the PCR products. (B) Pol II ChIP for strains grown in YES. Labeled PCR products were resolved on polyacrylamide gels and detected by autoradiography. The asterisk indicates the position of the PCR product from a nontranscribed region. $(C)$ Quantification from four independent experiments; the error bars indicate the standard error. (D) Schematic showing the position of probes used for TRO. (E) TRO was performed on $r r p 6 \Delta$ cells grown in EMMG $\left(0\right.$ and $10 \mathrm{mM} \mathrm{KH}_{2} \mathrm{PO}_{4}$ for $\left.4 \mathrm{~h}\right)$. (F) Schematic diagram showing the primer used for the RT and PCR product. (G) RT-PCR analysis of read-through levels. Strains were grown in YES medium. See also Supplemental Figures 3 and 4. 
pared transcription termination efficiency with each of the single mutants. In agreement with a complementary contribution of both proteins to $3^{\prime}$ end formation, additive accumulation of read-through RNA was observed in the double mutant compared with single $\operatorname{rrp} 6 \Delta$ or $d h p 1$ mutants (Supplemental Fig. 4C, lanes 2,4,6). Readthrough transcripts from pho1 were also detected in the pfs2-11 mutant, which harbors a mutation in Pfs2, an integral component of the CPF complex (Roguev et al. 2004; Wang et al. 2005).

As both prt and pho1 RNAs are transcribed from the pho1 locus under repressive conditions and share the same 3' end, it was not clear whether both transcripts require a functional exosome complex for proper transcription termination. To address this, TRO analysis was performed in rrp6s in the presence and absence of phosphate. In agreement with the Pol II ChIP data (Fig. $5 \mathrm{C})$, transcribing polymerase was found in this mutant beyond the pA site (Fig. 5D,E, probes 5,6). Remarkably, the termination defect was seen specifically under repressive conditions when prt RNA is transcribed but not when pho1 mRNA is transcribed. Furthermore, 3 '-extended transcripts were no longer detected in $\operatorname{rrp} 6 \Delta$ when the prt promoter was deleted (Fig. 5F,G, lanes 4,6). In contrast, deletion of the mRNA promoter had no effect on accumulation of the 3 '-extended transcripts in $\operatorname{rrp} 6 \Delta$ (Fig. $5 \mathrm{G}$, lane 5). These results demonstrate that transcription of ncRNA but not mRNA relies on the exosome for transcription termination, suggesting that coupling between $3^{\prime}$ end formation and RNA degradation might be an evolutionarily conserved feature of eukaryotic transcription.

To rule out the possibility that the transcription termination defect in the exosome mutant is linked to elevated H3K9me2 levels in this strain (Fig. 4B), we tested whether elevated $\mathrm{H} 3 \mathrm{~K} 9 \mathrm{me} 2$ levels can be observed in other mutants defective in $3^{\prime}$ end formation (dhp1 and pfs2-11). Results of this experiment demonstrate no change in H3K9me2 levels (Supplemental Fig. 5A,B). Reciprocally, we also examined whether $\mathrm{H} 3 \mathrm{~K} 9$ me contributes to transcription termination at pho1 (Supplemental Fig. 5C,D). RT-PCR analysis in ago1 $\operatorname{rrp} 6 \Delta, \operatorname{clr} 4 \Delta \operatorname{rrp} 6 \Delta$, and $d c r 1 \Delta$ rrp $6 \Delta$ mutants revealed no effect on the readthrough levels compared with each of the single mutants, arguing against a connection between heterochromatin formation and transcriptional termination.

\section{Mmil is required for recruitment of the exosome and RNAi complexes to prt}

Our data imply that transcription termination of prt RNA and its stability are dependent on the exosome complex. This strongly suggests that the exosome is specifically recruited to prt RNA but not pho1 mRNA already during transcription. Indeed, genome-wide analysis of Rrp6 recruitment to chromatin using Dam-ID revealed the presence of Rrp6 within the pho1 locus (Woolcock et al. 2012). However, the low resolution of this technique did not allow us to estimate where, exactly, Rrp6 is recruited. prt RNA and pho1 mRNA share the same 3 ' termini, and the only feature that differs between the two transcripts is the $1.2-\mathrm{kb} 5^{\prime}$ region. Thus, we searched for the presence of sequence elements known to target the exosome complex to RNA. Indeed, a cluster of DSR elements can be found in this region (Fig. 6A). These sequences are known to be recognized by $\mathrm{Mmil}$. In contrast, there are no obvious DSR clusters within the region shared by prt and pho1 RNAs.

To determine whether Mmil is indeed recruited to prt, we performed Mmil pull-down followed by RNA extraction from a strain expressing HTP (6xHis-TEV-proteinA)tagged Mmil and a nontagged control (Supplemental Fig. 6A). Mmil-bound RNA was then analyzed by RT-PCR (Fig. 6B). In agreement with published data, sme2 RNA was enriched in the pull-down from the Mmil-HTP strain but not in the control sample (Fig. 6B, lanes 1,2). Importantly, enrichment of prt RNA was also observed, suggesting that Mmil binds to this RNA. Moreover, deletion of the DSR element results in the loss of Mmil binding to prt but not to sme2 (Fig. 6B, lanes 2,3). These results support the notion that Mmil binds to prt directly. No signal was detected in the -RT control. Abundant rps15-2 RNA, which lacks DSR elements, was pulled down nonspecifically at equal levels for all samples.

To test whether Mmil binding plays a functional role, we analyzed pho1 levels in mmils. Interestingly, elevated levels of prt RNA were observed, although the effect was less pronounced than in $\operatorname{rrp} 6 \Delta$ (Fig. 6C, lanes $2,4)$. We next wanted to test whether loss of Mmil can also lead to a transcription termination defect. Similar to rrp6s, higher levels of Pol II were detected past the pho1 pA in mmi1s compared with the parental strain (Fig. 6D,E). Similarly, in a DSR $\Delta$ strain, increased Pol II levels were observed past the pA site (Fig. 6F). An increase in Pol II levels across the pho1 gene body was detected as well (Supplemental Fig. 6B,C). This transcriptional effect coincides with a stabilization of prt RNA in this strain (Supplemental Fig. 6D). We conclude that Mmil binds to prt RNA via recognition of the DSR elements and mediates transcription termination and subsequent degradation of prt by the exosome. In addition to Mmil, Red1 has also been implicated in recruiting the exosome to meiotic transcripts for degradation. Indeed, in agreement with the proposed role for Red1 in RNA decay, accumulation of prt was observed in a red1s strain (Supplemental Fig. 2D). Surprisingly, in contrast to Mmil, deletion of Red1 did not lead to defective termination (Supplemental Fig. 2E).

Next, we asked whether loss of exosome recruitment to prt can also lead to heterochromatic silencing at pho1, as seen in $\operatorname{rrp} 6 \Delta$. Surprisingly, loss of H3K9me2 marks was observed in a mmi1s mutant (Fig. 6G). This is in striking contrast to the $\operatorname{rrp} 6 \Delta$ mutant, where increased levels of H3K9me2 were detected (Fig. 4B). These results suggest that Mmil is required for $\mathrm{H} 3 \mathrm{~K} 9 \mathrm{me} 2$ at pho1 and might explain the increased Pol II levels in the DSR $\Delta$ strain (Supplemental Fig. 6C). Furthermore, consistent with the role of Mmil in RITS recruitment, a reduction in Agol levels across the pho1 locus was observed in the absence of Mmil (Supplemental Fig. 6E). We conclude that Mmil targeting is not restricted to meiotic transcripts only, in contrast to what was previously suggested. 

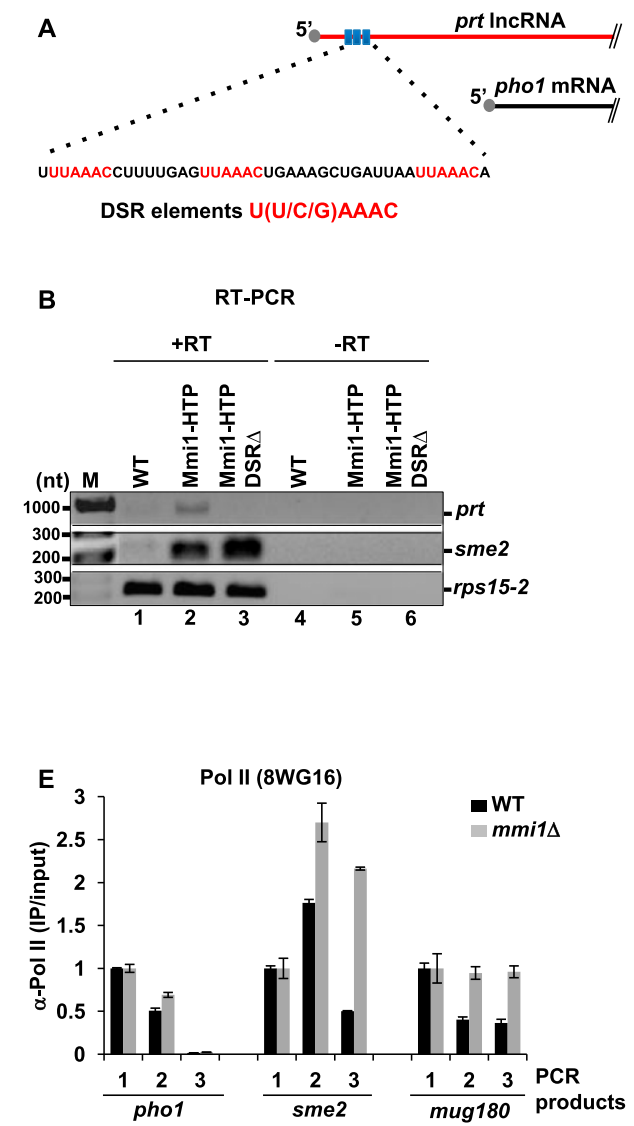
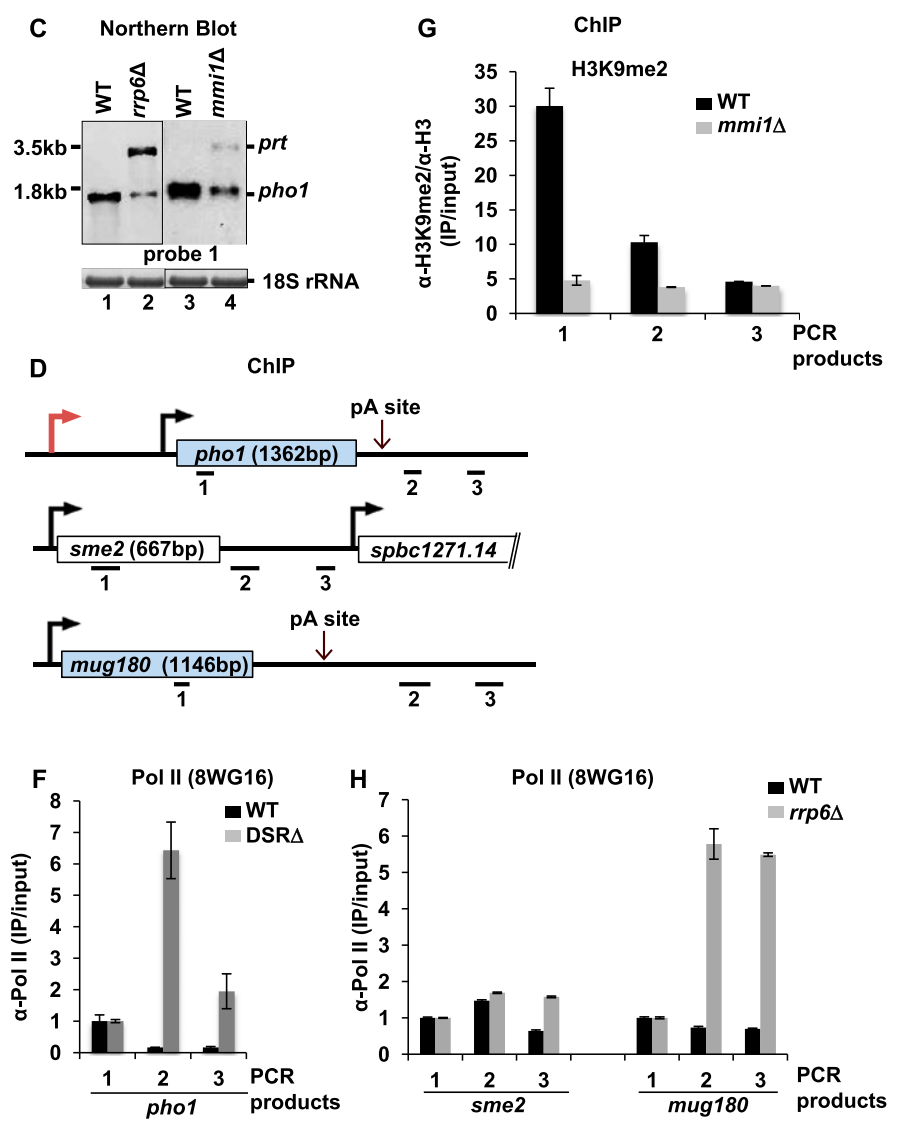

Figure 6. Mmil binds to prt and contributes to transcription termination and silencing at the pho1 locus. (A) Schematic showing three DSR elements (in red) in prt. (B) RT-PCR analysis of Mmil-bound RNA. (C) Northern blot analysis of pho1 in rrp6 $\Delta$, mmi1s, and their parental strains grown in YES. $(D)$ Schematic of the loci analyzed in $E-H$. Black bars indicate the location of the products amplified by quantitative PCR. All strains were grown in YES. (E) Pol II ChIP in wild-type (WT) and mmi1s strains. Immunoprecipitation signals were normalized to the signal of the gene body (probe 1; shown in $D) .(F)$ Pol II ChIP in wild-type and DSR $\Delta$ strains. Immunoprecipitation signals were normalized to the signal of probe 1 (shown in $D$ ). $(G)$ H3K9me2 levels across pho1 in mmi1s and wild-type strains grown in YES. Schematic depicting the position of PCR products is depicted in Figure 4A. (H) Pol II ChIP in wild-type and rrp6s strains. Immunoprecipitation signals were normalized to the signal of the gene body (probe 1; shown in $D$ ). See also Supplemental Figures 5 and 6.

\section{prt acts in cis to repress phol}

As prt accumulation coincides with a down-regulation of pho1 expression, we next asked whether prt can act in trans. We expressed prt with and without DSR elements from a plasmid. To ensure that only prt was produced, pho1 promoter was deleted in these constructs. These plasmids or empty vector were transformed into strains lacking the prt promoter at the chromosomal locus and into wild-type cells (Supplemental Fig. 6F). As shown in Supplemental Figure 6G, plasmid-driven prt RNA is expressed and can be stabilized when DSR elements are not present. However, no effect on pho1 mRNA levels was observed, suggesting that prt acts in cis at pho1, in contrast to the mechanisms involved in the formation of constitutive heterochromatin, where ncRNAs can act in cis and in trans.

\section{Generality of exosome-mediated transcription termination}

Finally, we wanted to investigate whether other genes are also dependent on Mmil and the exosome for transcription termination. ChIP analysis of Pol II occupancy was performed across sme2 and mug180 genes in $\operatorname{rrp} 6 \Delta$ and mmi1s mutants compared with their corresponding parental strains (Fig. 6D,E,H). These genes were selected for analysis because of the longer intergenic regions downstream as compared with other meiotic transcripts that are more densely positioned. A substantial increase in Pol II read-though levels downstream from sme2 and mug180 genes in the mutant strains was detected compared with wild type, consistent with a defective transcription termination.

During meiosis, Mmil is sequestered away from meiotic transcripts, leading to their increased expression (Yamamoto 2010). To test how the absence of Mmil affects Pol II termination in meiotic cells, we performed analysis of Pol II levels during a meiotic time course. As expected, at 2 and $4 \mathrm{~h}$ of induction, accumulation of mug180 RNA was observed (Supplemental Fig, 6H,I). At these time points, Pol II levels past the pA site stayed unchanged (Supplemental Fig. 6J). Intriguingly, after 6 and $8 \mathrm{~h}$ of induction, increased levels of Pol II downstream 
from mug180 were observed. This might suggest that Mmil sequestering leads to a transcription termination defect, allowing the fine-tuning of functional RNA levels during the course of meiosis. However, further analysis is required to support this hypothesis.

\section{Discussion}

ncRNAs originating from intergenic regions are prevalent in eukaryotes, including fission yeast. However, their function is largely unknown (Reinheckel et al. 2012). Evidence is emerging that cells can initiate widespread changes in gene expression in response to environmental stresses (Kim et al. 2012; Weiner et al. 2012). Interestingly, these studies showed that many stress response genes are associated with overlapping nc transcription. Phosphate response in $S$. pombe requires the product of the pho1 gene, which encodes a secreted acid phosphatase (Henry et al. 2011). Previous studies of pho1 repression in response to phosphate identified a $2-\mathrm{kb}$ region upstream of the pho1 ORF as a phosphate-sensing element (CarterO'Connell et al. 2012). However, the mechanism of repression was unclear. In this study, we identified the overlapping ncRNA (prt) transcribed from this region. Our results indicate that transcription of prt RNA plays a role in silencing of the pho1 gene at least in part by RNAi-mediated deposition of repressive chromatin modifications (H3K9me2). Accordingly, loss of nc transcription or deletion of RNAi components resulted in the loss of H3K9me2. This is in good agreement with a recent study that also reports a correlation between transcrip- tion upstream of the pho1 gene and H3K9me2 at this locus (Lee et al. 2013).

Interestingly, we show that in a Clr4 mutant where $\mathrm{H} 3 \mathrm{~K} 9 \mathrm{me} 2$ is abolished, the kinetics of pho1 induction in response to phosphate depletion are affected, suggesting a functional role for RNAi in the regulation of pho1 expression. In agreement with the previous findings that RNAi-mediated formation of stable heterochromatic regions at centromeres and telomeres depends, paradoxically, on Pol II transcription (Buhler and Moazed 2007), our data suggest that formation of a localized heterochromatin is also dependent on transcription and, at least in the case of the pho1 locus, relies on overlapping nc transcription.

In contrast, under phosphate deprivation, prt expression was abolished, and silencing marks lost, leading to the higher levels of Phol needed to allow increased uptake of phosphate (Fig. 7). Therefore, heterochromatin at the pho1 locus is only transient and dynamically responds to environmental cues. Interestingly, a recent study in plants (Arabidopsis) identified another example of transient heterochromatin formed in response to environmental stress (temperature) (Tittel-Elmer et al. 2010) to fine-tune gene expression. We therefore speculate that lncRNA-mediated silencing could allow cells to respond efficiently to environmental cues and modulate gene expression that needs to be delicately balanced and might, therefore, be advantageous for the cell. The dependence of prt function on the same system that mediates silencing of meiotic genes during vegetative growth (exosome/Mmil) could indicate a potential requirement

A pho1 induced $\left(0 \mathrm{mM} \mathrm{KH}_{2} \mathrm{PO}_{4}\right)$
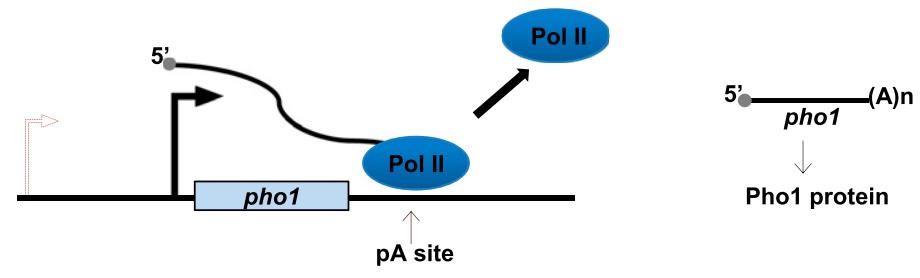

B

pho1 repressed $\left(10 \mathrm{mM} \mathrm{KH}_{2} \mathrm{PO}_{4}\right)$
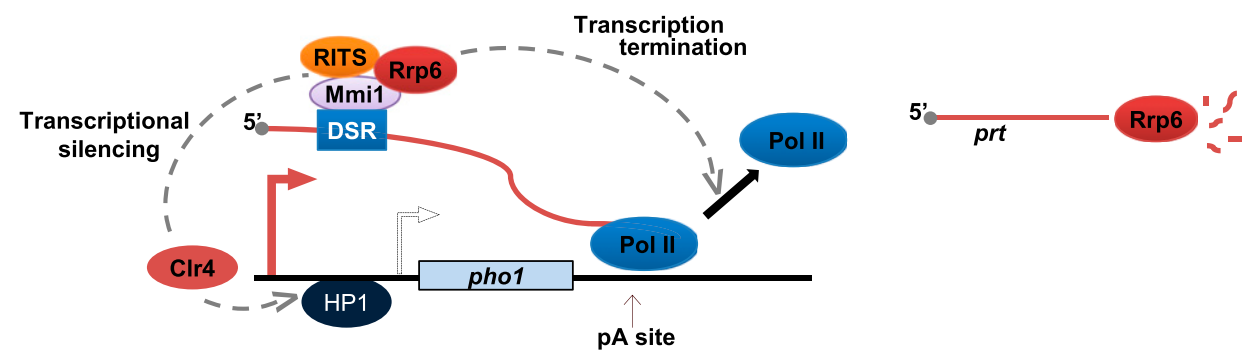

Figure 7. prt transcription regulates pho1 expression in response to phosphate. $(A)$ pho1 levels are induced in the absence of phosphate. Under these conditions, prt is not transcribed. $(B)$ In the presence of phosphate, transcription of prt leads to deposition of H3K9me2 marks at pho1. This requires Mmi1, Red1, Clr4, and the RITS complex. The resulting prt is degraded by the exosome. Furthermore, prt requires the exosome and $\mathrm{Mmil}$ for proper transcription termination coupled to turnover. 
for optimal phosphate levels during meiosis. Indeed, in support of this possibility, increased levels of pho1 RNA were observed during nitrogen starvation, which initiates the meiotic program (Wilhelm et al. 2008).

Previous studies in S. cerevisiae, where RNAi was lost during evolution (Drinnenberg et al. 2009, 2011), proposed several mechanisms by which nc transcription can repress adjacent genes. These include promoter occlusion, transcriptional interference, and repositioning of repressive chromatin modifications. One such example is the repression of the $\mathrm{PHO} 84$ gene, which is also a part of the phosphate response (Camblong et al. 2007). In this model, an antisense lncRNA facilitates recruitment of the histone deacetylase Hdal and thus repression of PHO84. Silencing at $\mathrm{PHO} 84$ is enhanced in rrp64, coincident with higher levels of nc transcription (Castelnuovo et al. 2013). It was proposed that this is due to defective Nrd1 recruitment and premature transcription termination of the antisense RNA in $\operatorname{rrp} 6 \Delta$.

Additionally, a recent study showed that the Nrd1 complex associates with not only sn/snoRNAs and CUTs but also many lncRNAs (Creamer et al. 2011), which may indicate that the role of the Nrd1 complex in transcription termination is broader than previously thought. While it is not clear how the exosome affects Nrd1 recruitment at $P H O 84$, it is certainly possible that a role of the exosome complex in transcription termination might not be limited to fission yeast. In support of this, a recent genome-wide high-resolution transcriptome analysis in budding yeast demonstrated the accumulation of 3 '-extended sn/snoRNA species in addition to expected precursor molecules in exosome mutants (Gudipati et al. 2012). Further studies are needed to find out whether the exosome can indeed affect Pol II termination in budding yeast or rather plays a role in quality control by degrading read-through products of leaky Nrdl termination.

The exosome complex is well characterized for its role in quality control, and prt (like CUTs) is destined for decay. The role of the exosome in $3^{\prime}$ end formation by post-transcriptional exonucleolytic trimming is well described for sn/snoRNAs and a particular mRNA (CTH2) (Ciais et al. 2008). We show that the exosome is also essential for the $3^{\prime}$ end formation of prt by promoting transcription termination. Loss of exosome recruitment to prt also results in defective termination, as we saw in rrp6s, suggesting that the exosome is likely to play a direct role in this process. It is possible that the exosome mediates recruitment of a termination factor. In support of this idea, it has been shown that Rrp6 can assist the Nrdl complex in terminating transcription at $\mathrm{PHO} 4 \mathrm{in}$ budding yeast (Castelnuovo et al. 2013). Although fission yeast has a Nrd1 homolog, Seb1 (Marina et al. 2013), whether it has a role in transcription termination is not known. It is also possible that Rrp6 can assist in mediating cleavage of the transcript, as it has been shown that lack of cleavage at the pA site results in defective Rat1dependent transcription termination (Birse et al. 1998). However, the additive increase in the levels of 3 '-extended read-through RNAs from the pho1 gene observed in the double mutant rrp6sdhp1-ts, compared with each of the single mutants, argues against the exosome acting in the same pathway with Rat 1 and suggests that they are more likely to act in parallel.

Surprisingly, it appears that prt has a discrete $3^{\prime}$ end at the canonical pA site, in contrast to the reported heterogeneity in the $3^{\prime}$ termini of Nrd1-dependent transcripts. Since prt is only detected in rrp6s cells when decaycoupled termination is lost due to deletion of Rrp6, it is possible that prt is cleaved and polyadenylated posttranscriptionally by the CPF. This would imply that prt $3^{\prime}$ end processing is not coupled to termination, in contrast to the most common mechanism in which these processes are intimately connected (Birse et al. 1998; Kim et al. 2004b, 2006; Luo et al. 2006). In the absence of Rrp6, prt may also be recognized and cleaved cotranscriptionally at the pA site by the CPF, followed by the Xrn2/Rat1/ Dhp1-mediated termination that normally operates at protein-coding genes. In support of this idea, it was previously described that an alternative termination mechanism can act as a "fail-safe" mechanism to rescue polymerases failing to terminate when the main termination pathway is compromised (Rondón et al. 2009).

Alternatively, the discrete 3 ' end of prt in rrp $6 \Delta$ cells could be produced by the exosome core. In this case, the endonucleolytic activity responsible for the cleavage at the pA site could potentially be provided by Dis3.

Although more in-depth studies are required to uncover the mechanistic details of exosome function in transcription termination, our results strongly suggest that the contribution of the exosome to gene regulation must be evaluated at the level of not only RNA stability but also transcription. Intriguingly, we observed that the transcription termination defect in exosome mutants (rrp6s and dis3-54) coincides with increased H3K9me2 and decreased Pol II occupancy at the pho1 locus. In agreement with our findings, it was recently reported that some genomic loci display higher levels of H3K9me2 in rrp6s (Yamanaka et al. 2013); however, an explanation of this phenomenon has been lacking so far. It was previously demonstrated that defective transcription termination at convergent genes can lead to elevated H3K9me and transcriptional silencing (Gullerova and Proudfoot 2008). In contrast to convergent genes, our data suggest that defective transcription termination that yields single-stranded $3^{\prime}$-extended RNA is not sufficient to induce heterochromatin; overlapping antisense transcription may be required to form dsRNAs. Conversely, increased $\mathrm{H} 3 \mathrm{~K} 9 \mathrm{me}$ cannot account for defective transcription termination in the exosome mutant. It was proposed that the increased silencing in the absence of a functional exosome could be due to competition between the exosome and RNAi for binding to Mmil (Yamanaka et al. 2013). According to this model, lack of the exosome complex would favor recruitment of RNAi and lead to the increased $\mathrm{H} 3 \mathrm{~K} 9 \mathrm{me}$. In support of the proposed model, we show that, in contrast to the exosome mutants, an mmi1 mutant (where loss of both the exosome and RNAi is expected) shows no H3K9me, which would normally be observed upon loss of RNAi recruitment. 
In conclusion, we show that the role of the exosome complex at the pho1 locus is not confined to degradation of the prt lncRNA but also contributes to gene expression via the regulation of transcription termination. Altogether, our data reinforce the emerging view that the exosome complex contributes to gene regulation at multiple levels, such as post-transcriptional, transcriptional, and chromatin (Coy and Vasiljeva 2010). Further studies are required to understand the interplay between the exosome and RNAi in the regulation of gene silencing as well as the exact mechanism of exosome-dependent transcription termination.

\section{Materials and methods}

Yeast strains

Yeast strains used in this study are listed in Supplemental Table 1. Oligonucleotides are listed in Supplemental Table 2.

\section{Preparation of RNA and RT-PCR}

Copurified RNA extractions were performed as previously described (Vasiljeva and Buratowski 2006). Reverse transcription was performed in a total volume of $20 \mu \mathrm{L}$ using specific primers (Supplemental Table S2) with Transcriptor reverse transcriptase (Roche). A - RT control was included in each reaction. Four microliters of the RT reaction was used for PCR with Phire Hot start polymerase (New England Biolabs). Products were visualized on a $1 \%$ agarose gel.

\section{Northern blotting}

Northern blot experiments were performed as described in Vasiljeva and Buratowski (2006). Gene-specific PCR-generated fragments were used as probes using oligonucleotides listed in Supplemental Table S2.

\section{TRO}

TRO was performed as described in Birse et al. (1997). Singlestranded probes for pho1, gfr (gene-free region; Chr. II: 1149380$1149521)$, and $a d h 1$ were generated by in vitro transcription from pCR-Blunt II-TOPO-based (Invitrogen) plasmids.

\section{ChIP experiments}

ChIP procedures and quantification were performed as described (Keogh and Buratowski 2004; Kim et al. 2004a,b). Primers are listed in Supplemental Table S2. Antibodies against Agol (Abcam, 18190), H3 (Abcam, 1791), H3K9me2 (Abcam, 1220), and Rpb1 (Millipore, 8WG16) were used.

\section{Para-Nitrophenylphosphate (PNPP) assay}

Phol activity was analyzed using a previously described PNPP activity assay (Schweingruber et al. 1986). S. pombe cells were grown in EMMG with $10 \mathrm{mM} \mathrm{KH}_{2} \mathrm{PO}_{4}$ to $\mathrm{OD}\left(\mathrm{A}_{600}\right)=0.5$ and

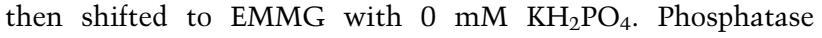
activity was assayed via incubation with $200 \mu \mathrm{L}$ of PNPP reagent $(5.6 \mu \mathrm{g} / \mathrm{mL})$ for $10 \mathrm{~min}$ at room temperature. The reaction was stopped by addition of $360 \mu \mathrm{L}$ of saturated $\mathrm{Na}_{2} \mathrm{CO}_{3}$ solution. Products of the reaction were measured at $\mathrm{OD}\left(\mathrm{A}_{400}\right)$ against $\mathrm{Na}_{2} \mathrm{CO}_{3}$ while normalizing for $\mathrm{OD}\left(\mathrm{A}_{600}\right)$.

\section{Acknowledgments}

We thank our colleagues at the University of Oxford, in particular Nick Proudfoot, Chris Norbury, Monika Gullerova, and Beth Watts for their valuable comments on the manuscript and helpful discussions. We thank Chris Norbury and Daniel Scott for help with cRACE experiments. We also thank Niko AminWetzel for his valuable help at the initial stage of this project. We are very grateful to Andre Verdel, Dennis Wykoff, Mario Halic, Marc Bühler, Jürg Bähler, Shiv Grewal, Monika Gullerova, and Chris Norbury for strains. This work was supported by a SKP Scholarship from Exeter College and a Hilla Ginwala Scholarship to S.S., a studentship from the MRC to S.W., Deutsche Forschungsgemeinschaft (DFG; Ki 1657/1-1) and the Swiss National Science Foundation (SNSF; PBBSP3-138760) to C.K., and the Wellcome Trust Research and Career Development fellowship to L.V.

\section{References}

Arigo JT, Eyler DE, Carroll KL, Corden JL. 2006. Termination of cryptic unstable transcripts is directed by yeast RNA-binding proteins Nrd1 and Nab3. Mol Cell 23: 841-851.

Birse CE, Lee BA, Hansen K, Proudfoot NJ. 1997. Transcriptional termination signals for RNA polymerase II in fission yeast. EMBO J 16: 3633-3643.

Birse CE, Minvielle-Sebastia L, Lee BA, Keller W, Proudfoot NJ. 1998. Coupling termination of transcription to messenger RNA maturation in yeast. Science 280: 298-301.

Buhler M, Moazed D. 2007. Transcription and RNAi in heterochromatic gene silencing. Nat Struct Mol Biol 14: 10411048.

Buhler M, Verdel A, Moazed D. 2006. Tethering RITS to a nascent transcript initiates RNAi- and heterochromatindependent gene silencing. Cell 125: 873-886.

Cam HP, Chen ES, Grewal SIS. 2009. Transcriptional scaffolds for heterochromatin assembly. Cell 136: 610-614.

Camblong J, Iglesias N, Fickentscher C, Dieppois G, Stutz F. 2007. Antisense RNA stabilization induces transcriptional gene silencing via histone deacetylation in S. cerevisiae. Cell 131: 706-717.

Carter-O'Connell I, Peel MT, Wykoff DD, O'Shea EK. 2012. Genome-wide characterization of the phosphate starvation response in Schizosaccharomyces pombe. BMC Genomics 13: 697.

Castelnuovo M, Rahman S, Guffanti E, Infantino V, Stutz F, Zenklusen D. 2013. Bimodal expression of PHO84 is modulated by early termination of antisense transcription. Nat Struct Mol Biol 20: 851-858.

Ciais D, Bohnsack MT, Tollervey D. 2008. The mRNA encoding the yeast ARE-binding protein Cth2 is generated by a novel 3'processing pathway. Nucleic Acids Res 36: 3075-3084.

Colmenares SU, Buker SM, Buhler M, Dlakic M, Moazed D. 2007. Coupling of double-stranded RNA synthesis and siRNA generation in fission yeast RNAi. Mol Cell 27: 449461.

Coy S, Vasiljeva L. 2010. The exosome and heterochromatin: Multilevel regulation of gene silencing. Adv Exp Med Biol 702: 105-121.

Creamer TJ, Darby MM, Jamonnak N, Schaughency P, Hao H, Wheelan SJ, Corden JL. 2011. Transcriptome-wide binding sites for components of the Saccharomyces cerevisiae nonpoly(A) termination pathway: Nrd1, Nab3, and Sen1. PLoS Genet 7: e1002329.

Djupedal I, Portoso M, Spahr H, Bonilla C, Gustafsson CM, Allshire RC, Ekwall K. 2005. RNA Pol II subunit Rpb7 
promotes centromeric transcription and RNAi-directed chromatin silencing. Genes Dev 19: 2301-2306.

Drinnenberg IA, Weinberg DE, Xie KT, Mower JP, Wolfe KH, Fink GR, Bartel DP. 2009. RNAi in budding yeast. Science 326: $544-550$.

Drinnenberg IA, Fink GR, Bartel DP. 2011. Compatibility with killer explains the rise of RNAi-deficient fungi. Science 333: 1592.

Gerace EL, Halic M, Moazed D. 2010. The methyltransferase activity of Clr4Suv39h triggers RNAi independently of histone H3K9 methylation. Mol Cell 39: 360-372.

Greger IH, Aranda A, Proudfoot N. 2000. Balancing transcriptional interference and initiation on the GAL7 promoter of Saccharomyces cerevisiae. Proc Natl Acad Sci 97: 84158420.

Gudipati RK, Villa T, Boulay J, Libri D. 2008. Phosphorylation of the RNA polymerase II C-terminal domain dictates transcription termination choice. Nat Struct Mol Biol 15: 786794.

Gudipati RK, Xu Z, Lebreton A, Seraphin B, Steinmetz LM, Jacquier A, Libri D. 2012. Extensive degradation of RNA precursors by the exosome in wild-type cells. Mol Cell 48: 409-421.

Gullerova M, Proudfoot NJ. 2008. Cohesin complex promotes transcriptional termination between convergent genes in $S$. pombe. Cell 132: 983-995.

Gullerova M, Proudfoot NJ. 2010. Transcriptional interference and gene orientation in yeast: Noncoding RNA connections. Cold Spring Harb Symp Quant Biol 75: 299-311.

Hainer SI, Pruneski JA, Mitchell RD, Monteverde RM, Martens JA. 2011. Intergenic transcription causes repression by directing nucleosome assembly. Genes Dev 25: 29-40.

Harigaya Y, Tanaka H, Yamanaka S, Tanaka K, Watanabe Y, Tsutsumi C, Chikashige Y, Hiraoka Y, Yamashita A, Yamamoto M. 2006. Selective elimination of messenger RNA prevents an incidence of untimely meiosis. Nature 442: 45-50.

Henry TC, Power JE, Kerwin CL, Mohammed A, Weissman JS, Cameron DM, Wykoff DD. 2011. Systematic screen of Schizosaccharomyces pombe deletion collection uncovers parallel evolution of the phosphate signal transduction pathway in yeasts. Eukaryot Cell 10: 198-206.

Hiriart E, Vavasseur A, Touat-Todeschini L, Yamashita A, Gilquin B, Lambert E, Perot J, Shichino Y, Nazaret N, Boyault C, et al. 2012. Mmil RNA surveillance machinery directs RNAi complex RITS to specific meiotic genes in fission yeast. $E M B O$ J 31: 2296-2308.

Hong EJ, Villen J, Gerace EL, Gygi SP, Moazed D. 2005. A cullin E3 ubiquitin ligase complex associates with Rik1 and the Clr4 histone H3-K9 methyltransferase and is required for RNAi-mediated heterochromatin formation. RNA Biol 2: 106-111.

Houseley J, Rubbi L, Grunstein M, Tollervey D, Vogelauer M. 2008. A ncRNA modulates histone modification and mRNA induction in the yeast GAL gene cluster. Mol Cell 32: 685695.

Iida T, Nakayama J, Moazed D. 2008. siRNA-mediated heterochromatin establishment requires HP1 and is associated with antisense transcription. Mol Cell 31: 178-189.

Kato H, Goto DB, Martienssen RA, Urano T, Furukawa K, Murakami Y. 2005. RNA polymerase II is required for RNAi-dependent heterochromatin assembly. Science 309: 467-469.

Keogh MC, Buratowski S. 2004. Using chromatin immunoprecipitation to map cotranscriptional mRNA processing in Saccharomyces cerevisiae. Methods Mol Biol 257: 1-16.
Kim M, Ahn SH, Krogan NJ, Greenblatt JF, Buratowski S. 2004a. Transitions in RNA polymerase II elongation complexes at the 3' ends of genes. EMBO I 23: 354-364.

Kim M, Krogan NJ, Vasiljeva L, Rando OJ, Nedea E, Greenblatt JF, Buratowski S. 2004b. The yeast Rat1 exonuclease promotes transcription termination by RNA polymerase II. Nature 432: 517-522.

Kim M, Vasiljeva L, Rando OJ, Zhelkovsky A, Moore C, Buratowski S. 2006. Distinct pathways for snoRNA and mRNA termination. Mol Cell 24: 723-734.

Kim T, Xu Z, Clauder-Munster S, Steinmetz LM, Buratowski S. 2012. Set3 HDAC mediates effects of overlapping noncoding transcription on gene induction kinetics. Cell 150: 11581169.

Lee NN, Chalamcharla VR, Reyes-Turcu F, Mehta S, Zofall M, Balachandran V, Dhakshnamoorthy J, Taneja N, Yamanaka S, Zhou M, et al. 2013. Mtr4-like protein coordinates nuclear RNA processing for heterochromatin assembly and for telomere maintenance. Cell 155: 1061-1074.

Luo W, Johnson AW, Bentley DL. 2006. The role of Rat1 in coupling mRNA 3 '-end processing to transcription termination: Implications for a unified allosteric-torpedo model. Genes Dev 20: 954-965.

Marina DB, Shankar S, Natarajan P, Finn KJ, Madhani HD. 2013. A conserved ncRNA-binding protein recruits silencing factors to heterochromatin through an RNAi-independent mechanism. Genes Dev 27: 1851-1856.

Martens JA, Laprade L, Winston F. 2004. Intergenic transcription is required to repress the Saccharomyces cerevisiae SER3 gene. Nature 429: 571-574.

Noma K, Sugiyama T, Cam H, Verdel A, Zofall M, Jia S, Moazed D, Grewal SI. 2004. RITS acts in cis to promote RNA interference-mediated transcriptional and post-transcriptional silencing. Nat Genet 36: 1174-1180.

Pinskaya M, Gourvennec S, Morillon A. 2009. H3 lysine 4 diand tri-methylation deposited by cryptic transcription attenuates promoter activation. EMBO I 28: 1697-1707.

Reinheckel T, Peters C, Kruger A, Turk B, Vasiljeva O. 2012. Differential impact of cysteine cathepsins on genetic mouse models of de novo carcinogenesis: Cathepsin B as emerging therapeutic target. Front Pharmacol 3: 133.

Roguev A, Shevchenko A, Schaft D, Thomas H, Stewart AF. 2004. A comparative analysis of an orthologous proteomic environment in the yeasts Saccharomyces cerevisiae and Schizosaccharomyces pombe. Mol Cell Proteomics 3: 125132.

Rondón AG, Mischo HE, Kawauchi J, Proudfoot NJ. 2009. Failsafe transcriptional termination for protein-coding genes in S. cerevisiae. Mol Cell 36: 88-98.

Rougemaille M, Libri D. 2010. Control of cryptic transcription in eukaryotes. Adv Exp Med Biol 702: 122-131.

Schweingruber ME, Fluri R, Maundrell K, Schweingruber AM, Dumermuth E. 1986. Identification and characterization of thiamin repressible acid phosphatase in yeast. I Biol Chem 261: 15877-15882.

Shobuike T, Tatebayashi K, Tani T, Sugano S, Ikeda H. 2001. The $\mathrm{dhp} 1^{+}$gene, encoding a putative nuclear $5^{\prime} \rightarrow 3^{\prime}$ exoribonuclease, is required for proper chromosome segregation in fission yeast. Nucleic Acids Res 29: 1326-1333.

Sugiyama T, Sugioka-Sugiyama R. 2011. Red1 promotes the elimination of meiosis-specific mRNAs in vegetatively growing fission yeast. $E M B O J$ 30: 1027-1039.

Tashiro S, Asano T, Kanoh J, Ishikawa F. 2013. Transcriptioninduced chromatin association of RNA surveillance factors mediates facultative heterochromatin formation in fission yeast. Genes Cells 18: 327-339. 
Shah et al.

Thiebaut M, Kisseleva-Romanova E, Rougemaille M, Boulay J, Libri D. 2006. Transcription termination and nuclear degradation of cryptic unstable transcripts: A role for the nrd1nab3 pathway in genome surveillance. Mol Cell 23: 853-864.

Tittel-Elmer M, Bucher E, Broger L, Mathieu O, Paszkowski J, Vaillant I. 2010. Stress-induced activation of heterochromatic transcription. PLoS Genet 6: e1001175.

Tuck AC, Tollervey D. 2013. A transcriptome-wide atlas of RNP composition reveals diverse classes of mRNAs and lncRNAs. Cell 154: 996-1009.

Vasiljeva L, Buratowski S. 2006. Nrd1 interacts with the nuclear exosome for 3' processing of RNA polymerase II transcripts. Mol Cell 21: 239-248.

Vasiljeva L, Kim M, Mutschler H, Buratowski S, Meinhart A. 2008a. The Nrd1-Nab3-Sen1 termination complex interacts with the Ser5-phosphorylated RNA polymerase II C-terminal domain. Nat Struct Mol Biol 15: 795-804.

Vasiljeva L, Kim M, Terzi N, Soares LM, Buratowski S. 2008b. Transcription termination and RNA degradation contribute to silencing of RNA polymerase II transcription within heterochromatin. Mol Cell 29: 313-323.

Verdel A, Jia S, Gerber S, Sugiyama T, Gygi S, Grewal SI, Moazed D. 2004. RNAi-mediated targeting of heterochromatin by the RITS complex. Science 303: 672-676.

Wang SW, Asakawa K, Win TZ, Toda T, Norbury CJ. 2005. Inactivation of the pre-mRNA cleavage and polyadenylation factor Pfs2 in fission yeast causes lethal cell cycle defects. Mol Cell Biol 25: 2288-2296.

Weiner A, Chen HV, Liu CL, Rahat A, Klien A, Soares L, Gudipati M, Pfeffner J, Regev A, Buratowski S, et al. 2012. Systematic dissection of roles for chromatin regulators in a yeast stress response. PLOS Biol 10: e1001369.

West S, Gromak N, Proudfoot NJ. 2004. Human 5' $\rightarrow 3^{\prime}$ exonuclease Xrn2 promotes transcription termination at co-transcriptional cleavage sites. Nature 432: 522-525.

Wilhelm BT, Marguerat S, Watt S, Schubert F, Wood V, Goodhead I, Penkett CJ, Rogers J, Bahler J. 2008. Dynamic repertoire of a eukaryotic transcriptome surveyed at singlenucleotide resolution. Nature 453: 1239-1243.

Woolcock KJ, Stunnenberg R, Gaidatzis D, Hotz HR, Emmerth S, Barraud P, Buhler M. 2012. RNAi keeps Atf1-bound stress response genes in check at nuclear pores. Genes Dev 26: 683-692.

Xiang S, Cooper-Morgan A, Jiao X, Kiledjian M, Manley JL, Tong L. 2009. Structure and function of the $5^{\prime} \rightarrow 3^{\prime}$ exoribonuclease Ratl and its activating partner Rail. Nature 458: 784-788.

Yamamoto M. 2010. The selective elimination of messenger RNA underlies the mitosis-meiosis switch in fission yeast. Proc Ipn Acad, Ser B, Phys Biol Sci 86: 788-797.

Yamanaka S, Mehta S, Reyes-Turcu FE, Zhuang F, Fuchs RT, Rong Y, Robb GB, Grewal SIS. 2013. RNAi triggered by specialized machinery silences developmental genes and retrotransposons. Nature 493: 557-560.

Zofall M, Yamanaka S, Reyes-Turcu FE, Zhang K, Rubin C, Grewal SIS. 2012. RNA elimination machinery targeting meiotic mRNAs promotes facultative heterochromatin formation. Science 335: 96-100. 


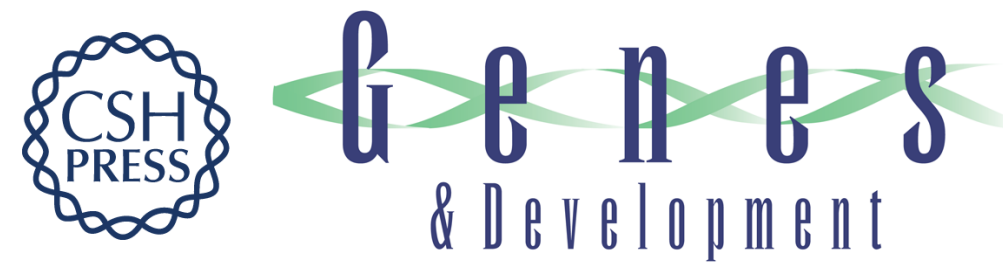

\section{IncRNA recruits RNAi and the exosome to dynamically regulate pho1 expression in response to phosphate levels in fission yeast}

Sneha Shah, Sina Wittmann, Cornelia Kilchert, et al.

Genes Dev. 2014, 28:

Access the most recent version at doi:10.1101/gad.230177.113

Supplemental http://genesdev.cshlp.org/content/suppl/2014/01/31/28.3.231.DC1
Material

References This article cites 65 articles, 22 of which can be accessed free at: http://genesdev.cshlp.org/content/28/3/231.full.html\#ref-list-1

Creative This article, published in Genes \& Development, is available under a Creative Commons Commons License (Attribution-NonCommercial 3.0 Unported), as described at License http://creativecommons.org/licenses/by-nc/3.0/.

Email Alerting Receive free email alerts when new articles cite this article - sign up in the box at the top Service right corner of the article or click here.

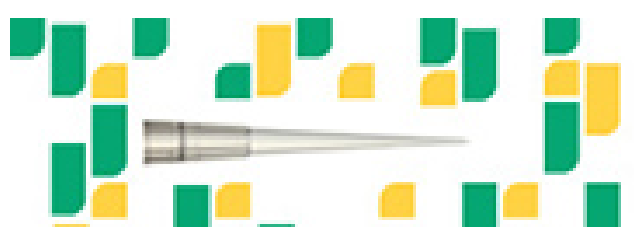

Focused on your science. 